\title{
Cancer patients and internal medicine patients attitude towards COVID-19 vaccination in Poland
}

\author{
Joanna Kufel-Grabowska ${ }^{1,2, A-D, F}$, Mikołaj Bartoszkiewicz ${ }^{3, B-D}$, Rodryg Ramlau ${ }^{4, E, F}$, Maria Litwiniuk ${ }^{5,6, E, F}$ \\ ${ }^{1}$ Department of Electroradiology, Poznan University of Medical Sciences, Poland \\ 2 Department of Chemotherapy, University Hospital of Lord's Transfiguration, Poznań, Poland \\ ${ }^{3}$ Department of Immunobiology, Poznan University of Medical Sciences, Poland \\ ${ }^{4}$ Department and Clinic of Oncology, Poznan University of Medical Sciences, Poland \\ ${ }^{5}$ Department of Chemotherapy, The Greater Poland Cancer Center, Poznań, Poland \\ ${ }^{6}$ Department of Cancer Pathology and Prevention, Poznan University of Medical Sciences, Poland \\ A - research concept and design; $\mathrm{B}$ - collection and/or assembly of data; $\mathrm{C}$ - data analysis and interpretation; \\ $\mathrm{D}$ - writing the article; $\mathrm{E}$ - critical revision of the article; $\mathrm{F}$ - final approval of the article
}

Address for correspondence

Mikołaj Bartoszkiewicz

E-mail:m.bartoszkiewicz@ump.edu.pl

Funding sources

None declared

Conflict of interest

None declared

Received on April 6, 2021

Reviewed on April 22, 2021

Accepted on June 15, 2021

Published online on July 20, 2021

Cite as

Kufel-Grabowska J, Bartoszkiewicz M, Ramlau R, Litwiniuk M.

Cancer patients and internal medicine patients attitude towards COVID-19 vaccination in Poland. Adv Clin Exp Med. 2021;30(8):805-811. doi:10.17219/acem/138962

DOI

10.17219/acem/138962

\section{Copyright}

Copyright by Author(s)

This is an article distributed under the terms of the

Creative Commons Attribution 3.0 Unported (CC BY 3.0)

(https://creativecommons.org/licenses/by/3.0/)

\section{Abstract}

Background. The initial approval of the Pfizer/BioNTech and Moderna vaccines by the European Medicines Agency (EMA) and Food and Drug Administration (FDA) marked a milestone in the fight against the COVID-19 pandemic. The increased public debate about the vaccine development process and vaccine side effects has activated the anti-vaccine community, which has begun to spread conspiracy theories about vaccine safety.

Objectives. Our study is the first to investigate the awareness of Polish patients suffering from various chronic diseases, mainly cancer, about vaccination against SARS-COV-2.

Materials and methods. An anonymous survey was made available from November 2020 to February 2021 to representatives of patient organizations through social media (Facebook) and to patients in the Chemotherapy Department of the Clinical Hospital in Poznań. The survey was completed by 836 patients. The majority of the survey respondents had cancer $(77 \%, n=644)$, and almost $1 / 5$ of the respondents indicated hypertension $(15.7 \%, n=131)$ as well as depression and/or anxiety disorders $(11.1 \%, n=93)$.

Results. Less than half of the respondents (43.5\%, $n=364$ ) believed that SARS-CoV-2 vaccines were safe (40.4\%, $n=260$, among cancer patients; $53.9 \%, n=104$, among patients with other medical conditions). More than half of the respondents $(60.5 \%, n=506)$ intended to be vaccinated against SARS-CoV-2 (58.8\%, $n=378$, among cancer patients; $66.3 \%, n=128$, among patients with other medical conditions). Fear of vaccine complications and lack of belief in vaccine effectiveness were prevalent among both cancer patients and patients with other medical conditions.

Conclusions. The vast majority of cancer and medical patients wanted to be vaccinated against COVID-19. More than half of the respondents did not believe that the COVID-19 vaccine would be safe for them. Education of cancer and medical patients on the safety and effectiveness of the vaccine, as well as the use of additional protective measures against infection, is an extremely important element of prevention during the COVID-19 pandemic.

Key words: infection, vaccine, cancer patients, COVID-19 


\section{Background}

Since the outbreak of the COVID-19 pandemic until February 13, 2021, nearly 108 million people worldwide have been infected with the coronavirus and 2.4 million have died. In Poland, 1.6 million cases have been confirmed and 41,000 people have lost their lives. ${ }^{1}$ Each year there are about 10 million cancer deaths worldwide. In Poland, 155,000 new cases are diagnosed and 93,000 die from cancer each year. ${ }^{2,3}$

On December 11, 2020, the United States Food and Drug Administration (FDA) approved the Pfizer vaccine against COVID-19 and on December 18, 2020, it approved the Moderna vaccine. In January 2021, the Astra Zeneca vaccine was approved for use in European Union countries. ${ }^{4,5}$

The risk of severe infection with SARS-CoV-2 is several times higher among patients with hematological malignancies, lung cancer, tumors at the stage of dissemination, and solid tumors up to 1 year after a diagnosis of cancer. In the general population, the risk is about $2-3 \%$, while among cancer patients it is $5-61 \%{ }^{6}$

Vaccines based on viral RNA (Comirnaty, Moderna) and vector vaccines (Astra Zeneca) can be safely used in cancer patients, even during cancer treatment. Their effectiveness depends on the current therapy (chemotherapy, immunotherapy, hormone therapy, targeted therapy), the general condition of the patient, coexisting diseases, and the type and severity of the cancer. Patients on cytostatic therapy may have lower immunization levels, whereas patients on immunotherapy and hormone therapy should have immune responses comparable to the healthy population. ${ }^{7,8}$

Optimally, vaccination should take place at least 14 days before beginning cancer therapy, but this should not be a reason to delay its initiation. The use of cytostatic drugs has an immunosuppressive effect; however, vaccination may be administered between courses of therapy, preferably after the time of the greatest decrease in white blood cell count and at least 2-3 days before the next dose, when there is the greatest risk of post-vaccination deterioration. During immunotherapy and hormone therapy, the use of vaccines is independent of the timing of drug administration..$^{9,10}$

This study presents a survey of attitudes about vaccination against COVID-19 among cancer and internal medicine patients in Poland in the early stages of the COVID-19 vaccination program.

\section{Objectives}

The aim of the conducted survey was to gather the opinions of Polish cancer patients and internal medicine patients about the SARS-CoV-2 vaccine and to study the consequences resulting from their decisions.

\section{Materials and methods}

\section{Study design}

This cohort study included 836 patients suffering from various chronic diseases. Data were collected from November 2020 to February 2021 from representatives of patient organizations through social media (Facebook) and patients from the Department of Chemotherapy at the University Hospital of Lord's Transfiguration in Poznań, Poland.

An anonymous survey entitled "Vaccination against SARSCoV-2 causing COVID-19" was used for this study. The survey was divided into 2 parts. The $1^{\text {st }}$ part (epidemiological) included questions about the patient (gender, age, place of residence, education, employment, coexisting diseases, and chronic treatment), whereas the $2^{\text {nd }}$ part asked about the patient's attitudes toward SARS-CoV-2 vaccination (willingness to be vaccinated, concerns about vaccines and effectiveness of protective measures in the face of the COVID-19 pandemic). The questionnaire was designed by the study authors and has not been validated.

\section{Inclusion criteria}

Patients in Poland with various diseases were eligible for this study. Completion of the survey was voluntary. Data were collected for 4 months without limiting the population.

\section{Statistical analyses}

IBM SPSS Statistics v. 26 (IBM Corp., Armonk, USA) software was used for the analysis. A $p$-value $<0.05$ was adopted as the level of statistical significance. The ShapiroWilk test was used to test the normality of the distribution. The $x^{2}$ test was used to investigate the interdependence of the data. The z-test was used to test for significant differences between percentages (Bonferroni correction was used to correct for multiple comparisons). The binomial test was used to compare whether the proportion of success on a two-level categorical dependent variable differed significantly from a hypothesized value. To study whether the distribution of quantitative data in more than 2 groups originated from the same distribution, the nonparametric Kruskal-Wallis test was chosen with the Bonferroni test used for post hoc tests (pairwise Mann-Whitney U test with Bonferroni correction).

\section{Ethics}

The survey was submitted to the bioethics commission, which ruled that, in the case of an anonymous survey, the approval of the bioethics commission is not needed. Each patient was informed about the voluntary nature study of the questionnaire survey and expressed verbal 
consent. All procedures were performed in accordance with the 1964 Declaration of Helsinki and its later amendments or comparable ethical standards.

\section{Results}

\section{Participants}

The survey was completed by 836 participants, and it included significantly more women $(92.1 \%, \mathrm{n}=770$, binomial test $\mathrm{p}<0.01$ more than $50 \%)$ than men $(7.9 \%, \mathrm{n}=66$, binomial test: $\mathrm{p}<0.01$, less than $50 \%$ ).

Most respondents came from cities with more than 250,000 residents $(34.9 \%, \mathrm{n}=292)$, followed by villages $(22.0 \%, \mathrm{n}=184)$ and cities with up to 50,000 residents $(20.3 \%, n=170)$; the fewest respondents were from cities with up to 100,000 residents $(13.5 \%, \mathrm{n}=113)$ and then cities with up to 250,000 residents $(9.2 \%, \mathrm{n}=77)$. The vast majority of respondents were employed $(71.8 \%, \mathrm{n}=600)$, almost $15 \%$ of the respondents were retired and $10.8 \%(\mathrm{n}=90)$ declared being unemployed. Almost all respondents had at least secondary education (60\% higher, $32.1 \%$ secondary), $7.2 \%$ had vocational education and $0.7 \%$ had primary education (Fig. 1).

More than 3/4 of the survey participants had cancer $(77.0 \%, \mathrm{n}=644)$, and almost $1 / 5$ of the respondents indicated hypertension $(15.7 \%, \mathrm{n}=131)$ as well as depression and/or anxiety disorders $(11.1 \%, \mathrm{n}=93)$. Less than $10 \%$ of respondents had the following conditions: migraine or frequent headaches $(9.4 \%, \mathrm{n}=79)$, obesity $(9.0 \%, \mathrm{n}=75)$, bronchial asthma $(5.3 \%, \mathrm{n}=44)$, osteoporosis $(4.9 \%, \mathrm{n}=41)$, hypothyroidism $(4.5 \%, \mathrm{n}=38)$, insulin resistance $(4.2 \%$, $\mathrm{n}=35)$, acne $(3.2 \%, \mathrm{n}=27)$, rheumatoid arthritis $(2.8 \%$, $\mathrm{n}=23)$, Hashimoto's thyroiditis $(2.6 \%, \mathrm{n}=22)$, kidney disease $(1.7 \%, \mathrm{n}=14)$, allergies $(1.4 \%, \mathrm{n}=12)$, atherosclerosis $(0.6 \%, n=5)$, gout, epilepsy (each $n=4,0.5 \%)$, hepatitis, thrombosis, pneumonia (each $n=3,0.4 \%$ ), stroke, endometriosis (each $n=2,0.2 \%$ ), and other diseases $(5.8 \%, n=48)$. The vast majority of patients were receiving chronic treatment $(78.6 \%, \mathrm{n}=657)$ (Table 1$)$.

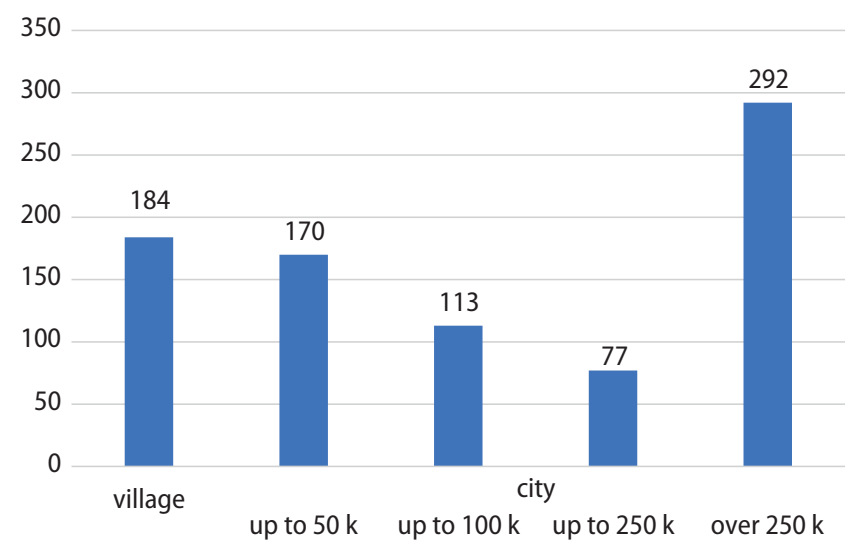

Fig. 1. Place of residence of the respodents
Table 1. The most common diseases by respondents

\begin{tabular}{|c|c|c|}
\hline Disease & Frequency & Percent \\
\hline Allergies & 12 & $1.4 \%$ \\
\hline Bronchial asthma & 44 & $5.3 \%$ \\
\hline Depression, anxiety disorders & 93 & $11.1 \%$ \\
\hline Cardiovascular disease & 35 & $4.2 \%$ \\
\hline Cancer & 644 & $77.0 \%$ \\
\hline Kidney disease & 14 & $1.7 \%$ \\
\hline Diabetes & 35 & $4.2 \%$ \\
\hline Gout & 4 & $0.5 \%$ \\
\hline Endometriosis & 2 & $0.2 \%$ \\
\hline Epilepsy & 4 & $0.5 \%$ \\
\hline Hashimoto & 22 & $2.6 \%$ \\
\hline Insulin resistance & 35 & $4.2 \%$ \\
\hline Migraine or frequent headaches & 79 & $9.4 \%$ \\
\hline Atherosclerosis & 5 & $0.6 \%$ \\
\hline Hypertension & 131 & $15.7 \%$ \\
\hline Hyperthyroidism & 1 & $0.1 \%$ \\
\hline Hypothyroidism & 38 & $4.5 \%$ \\
\hline Osteoporosis & 41 & $4.9 \%$ \\
\hline Obesity & 75 & $9.0 \%$ \\
\hline Rheumatoid arthritis & 23 & $2.8 \%$ \\
\hline Acne & 27 & $3.2 \%$ \\
\hline Stroke & 2 & $0.2 \%$ \\
\hline Viral hepatitis & 3 & $0.4 \%$ \\
\hline Thrombosis & 3 & $0.4 \%$ \\
\hline Pneumonia & 3 & $0.4 \%$ \\
\hline
\end{tabular}

\section{Main part of the survey}

Less than half of the respondents $(43.5 \%, \mathrm{n}=364)$ believed that SARS-CoV-2 vaccines were safe (40.4\% among cancer patients, $53.9 \%$ among patients with other medical conditions), while $13.5 \%(\mathrm{n}=113)$ had the opposite opinion and $42.9 \%(n=359)$ could not determine vaccine safety (Table 2, Q1). More than half of the respondents $(60.5 \%, \mathrm{n}=506)$ intended to be vaccinated against SARSCoV-2 (58.8\% among cancer patients, $66.3 \%$ among patients with other medical conditions), $17.5 \%(\mathrm{n}=146)$ did not plan to be vaccinated and more than $1 / 5(22.0 \%$, $\mathrm{n}=184$ ) had not yet made a decision (Table 2, Q2). Undecided individuals and vaccine opponents were most concerned about vaccine complications $(32.1 \%, \mathrm{n}=268)$, did not believe in vaccine effectiveness $(12.0 \%, \mathrm{n}=100)$ or believed that they did not need the vaccination because of their history of SARS-CoV-2 infection 3.9\% $(n=33)$ (Table 2, Q3). Fear of vaccine complications (33\% compared to $29 \%$ ) and lack of belief in vaccine effectiveness (12.6\% compared to $9.8 \%$ ) were prevalent among both cancer patients and patients with other medical conditions (Table 2). 
Table 2. Main part of survey - analysis of patients' responses

\begin{tabular}{|c|c|c|c|}
\hline Question & Answer & Frequency (n) & Percentage \\
\hline \multirow{3}{*}{$\begin{array}{l}\text { Q1. Do you think } \\
\text { the coronavirus vaccine } \\
\text { is safe? }\end{array}$} & No & 113 & 13.5 \\
\hline & I don't know & 359 & 42.9 \\
\hline & Yes & 364 & 43.5 \\
\hline \multirow{3}{*}{$\begin{array}{l}\text { Q2. Are you planning } \\
\text { to vaccinate against } \\
\text { the coronavirus? }\end{array}$} & No & 146 & 17.5 \\
\hline & I don't know & 184 & 22.0 \\
\hline & Yes & 506 & 60.5 \\
\hline \multirow{3}{*}{$\begin{array}{l}\text { Q3. If not, why not? (multiple } \\
\text { choice question) }\end{array}$} & I don't believe the vaccine will be effective & 100 & 12.0 \\
\hline & I am concerned about post-vaccination complications & 268 & 32.1 \\
\hline & I have had COVID-19 and do not need a vaccination & 33 & 3.9 \\
\hline \multirow{4}{*}{$\begin{array}{l}\text { Q4. If you are concerned } \\
\text { about vaccine complications, } \\
\text { what are they? (multiple } \\
\text { choice question) }\end{array}$} & Anaphylactic shock & 313 & 37.4 \\
\hline & Fever & 48 & 5.7 \\
\hline & Pain, redness at the injection site & 33 & 3.9 \\
\hline & Rash & 8 & 1.0 \\
\hline \multirow{4}{*}{$\begin{array}{l}\text { Q5. Why are you planning } \\
\text { to get vaccinated? (multiple } \\
\text { choice question) }\end{array}$} & I am worried about COVID-19 & 430 & 51.4 \\
\hline & I am afraid that I might infect someone from my relatives or patients & 349 & 41.7 \\
\hline & I want to get back to my social life/trips & 382 & 45.7 \\
\hline & I have had COVID-19 and want to avoid getting it again & 78 & 9.3 \\
\hline \multirow{4}{*}{$\begin{array}{l}\text { Q6. Do you think that } \\
\text { vaccination against } \\
\text { coronavirus should be } \\
\text { mandatory? (multiple choice } \\
\text { question) }\end{array}$} & Yes, for everyone & 273 & 32.7 \\
\hline & Yes, but only for people at risk (medics, police, army, teachers, chronically ill people) & 64 & 7.7 \\
\hline & Yes, for people traveling abroad & 51 & 6.1 \\
\hline & No, everyone should have a choice & 502 & 60.0 \\
\hline \multirow{4}{*}{$\begin{array}{l}\text { Q7. What do you think } \\
\text { can significantly reduce } \\
\text { the number of coronavirus } \\
\text { cases? (multiple choice } \\
\text { question) }\end{array}$} & Vaccinating entire societies & 579 & 69.3 \\
\hline & Use of personal protective equipment (masks, disinfection, gloves) & 564 & 67.5 \\
\hline & Limiting interpersonal contacts to the necessary minimum & 276 & 33. \\
\hline & Closing the state borders & 128 & 15.3 \\
\hline
\end{tabular}

When asked about vaccine complications, respondents were most often concerned about anaphylactic shock (37.4\%, $\mathrm{n}=313)$, followed by fever $(5.7 \%, \mathrm{n}=48)$, pain and redness at the injection site $(3.9 \%, \mathrm{n}=33)$, and rash $(1.0 \%$, $\mathrm{n}=8$ ) (Table 2, Q4).

More than half of the patients $(51.4 \%, \mathrm{n}=430)$ wanted to be vaccinated against SARS-CoV-2 due to fear of getting sick, $45.7 \%(n=382)$ wanted to return to social life and/or travel and $41.7 \%(n=349)$ wanted to be vaccinated due to fear of infecting a loved one; some patients $(3.9 \%$, $\mathrm{n}=78$ ) wanted to avoid reinfection with a new variant of coronavirus 2 (Table 2, Q5).

More than half of the respondents $(60.0 \%, \mathrm{n}=502)$ believed that everyone should be able to decide individually whether to participate in the SARS-CoV-2 vaccination program, while more than $1 / 4$ of the respondents $(32.7 \%$, $n=273$ ) stated that vaccination should be mandatory for everyone, and $6.1 \%(n=51)$ that it should be mandatory for international travelers (Table 2, Q6). A comparable number believed that vaccinating the public $(69.3 \%, \mathrm{n}=579)$ and using personal protective equipment (masks, disinfectants, gloves) $(67.5 \%, \mathrm{n}=564)$ could significantly reduce COVID-19 incidence (Table 2, Q7).

\section{Relationships of attitudes with respondent characteristics}

Age

We compared responses to the question if the coronavirus vaccine was safe between young people and the elderly. There was a significant difference between the age groups (Kruskal-Wallis test, $\mathrm{p}=0.0142$ ). To further investigate the differences, the Bonferroni post hoc test was used:

- The average age among those who do not believe the coronavirus vaccine is safe was significantly lower than among the group who believe it is safe (response "yes", Bonferroni post hoc test, $B=-70.938, p=0.006, M=45, n=364$ ) and who have no opinion (response "don't know", Bonferroni post hoc test, $\mathrm{B}=-71.952, \mathrm{p}=0.0066, \mathrm{M}=45, \mathrm{n}=112$ ).

- There were no significant difference in age distribution between the groups that answered "yes" and "I don't know" (Bonferroni post hoc test, $\mathrm{B}=1.015$, $\mathrm{p}=0.9555$ ).

- The younger the respondents, the more often they indicated that they would not be vaccinated because they had already been sick with COVID-19 ( $\mathrm{r}=-0.073$, $\mathrm{p}=0.0364$ ). Respondents who indicated that they would 
Table 3. Prerequisites for vaccination

\begin{tabular}{|c|c|c|c|c|}
\hline Prerequisite & No cancer $(n=193)$ & Cancer $(n=643)$ & z-test statistic & $\mathrm{p}$-value \\
\hline I am afraid of catching COVID-19 & $\begin{array}{c}n=101 \\
52.3 \%\end{array}$ & $\begin{array}{c}n=329 \\
51.2 \%\end{array}$ & 0.284 & 0.7795 \\
\hline I am afraid I might infect a relative or a patient & $\begin{array}{c}n=102 \\
52.8 \%\end{array}$ & $\begin{array}{c}n=247 \\
38.4 \%\end{array}$ & 3.567 & 0.0004 \\
\hline I want to get back to my social life/travels & $\begin{array}{c}n=104 \\
53.9 \%\end{array}$ & $\begin{array}{c}n=278 \\
43.2 \%\end{array}$ & 2.605 & 0.0091 \\
\hline I have had COVID-19 and want to avoid getting it again & $\begin{array}{c}n=18 \\
9.3 \%\end{array}$ & $\begin{array}{c}n=60 \\
9.3 \%\end{array}$ & 0.000 & 1.0000 \\
\hline
\end{tabular}

Values in bold are statistically significant.

not be vaccinated because they had already been sick with COVID-19 were significantly younger (Mann-Whitney $\mathrm{U}$ test; $\mathrm{U}=9685.000, \mathrm{p}=0.0375$ ).

- The younger the respondents, the more often they cited the desire to return to a social life and travel as the reason for vaccination $(\mathrm{r}=-0.082, \mathrm{p}=0.017)$. Respondents who cited the desire to return to a social life and travel as the reason for vaccination were significantly younger (Mann-Whitney U test; $\mathrm{U}=11814.500, \mathrm{p}=0.0424$ ).

- The older the respondents, the more often they cited fear of contracting COVID-19 as a reason for vaccination $(\mathrm{r}=0.119, \mathrm{p}=0.0013)$. Respondents who cited fear of contracting COVID-19 as a reason for vaccination were significantly older (Mann-Whitney U test; $\mathrm{U}=100007.000$; $\mathrm{p}=0.000)$.

\section{Place of residence}

There was a significant relationship between place of residence and answers given to the survey question $\left(x^{2}=24.263, \mathrm{p}=0.0022\right)$ :

- Respondents from bigger cities gave the fear of COVID-19 disease as a reason for vaccination significantly more often than people from smaller cities $\left(\chi^{2}=22.050, n=430\right.$; $\mathrm{p}=0.000)$.

- Respondents from bigger cities gave the desire to return to a social life as a reason for vaccination significantly more often than people from smaller cities $\left(X^{2}=17.116\right.$, $\mathrm{p}=0.002, \mathrm{n}=382$ ).

\section{Educational level}

There was a significant relationship between education level and answers given to the survey question $\left(\chi^{2}=37.234\right)$ :

- Respondents with higher education were significantly more likely to believe that the coronavirus vaccine was safe than those with a vocational education (z-test with Bonferroni correction, $\mathrm{z}=2.773, \mathrm{p}=0.0056$ ) or a secondary education (z-test with Bonferroni correction, $\mathrm{z}=4.524$, $\mathrm{p}<0.0001, \mathrm{n}=364)$.

- Respondents with higher education significantly more often perceived population vaccination as an effective means to reduce coronavirus incidence than those with vocational education (z-test with Bonferroni correction, $\mathrm{z}=4.136 \mathrm{p}<0.0001$ ) or secondary education ( $\mathrm{z}$-test with Bonferroni correction, $\mathrm{z}=4.772, \mathrm{p}<0.0001, \mathrm{n}=579$ ).

\section{Cancer}

There was a significant relationship between the presence of cancer and concerns about the safety of the coronavirus vaccine $\left(x^{2}=11.400, p=0.0031\right)$. In particular:

- Cancer patients were significantly less likely to believe that coronavirus vaccines are safe than non-cancer patients (z-test: $\mathrm{z}=3.305, \mathrm{p}=0.0009, \mathrm{n}=364$ ).

- No significant relationship between willingness to be vaccinated against coronavirus and presence of cancer was observed $\left(x^{2}=3.875, \mathrm{p}=0.1444, \mathrm{n}=506\right)$.

- Cancer patients were significantly less likely to intend to get vaccinated due to a desire to return to a social life than non-cancer patients ( $\mathrm{z}$-test: $\mathrm{z}=2.605, \mathrm{p}=0.0091$, $\mathrm{n}=382$ ).

The above data are summarized in Table 3.

\section{Discussion}

Our study is the first to investigate the awareness of Polish patients suffering from various chronic diseases, mainly cancer, about vaccination against SARS-CoV-2. Its results highlight the importance of this problem and draw attention to the need to educate these communities about the severe course and complications of coronavirus infection.

The successful completion of clinical trials for the use of SARS-CoV-2 vaccines was one of the highlights of 2020. The initial approval by the European Medicines Agency (EMA) and FDA of the Pfizer/BioNTech and Moderna vaccines marked a milestone in the fight against the COVID-19 pandemic. However, the increased public debate about the vaccine development process and vaccine side effects have activated the anti-vaccine community, which has begun to spread conspiracy theories about vaccine safety.

Previous studies analyzing morbidity and mortality due to COVID-19 confirm that the groups most vulnerable to severe SARS-CoV-2 infection are the elderly, those burdened with chronic diseases and cancer patients. In our 
study, all respondents were burdened with coexisting conditions, among which cancer predominated (77\%), followed by cardiovascular diseases (heart disease $4.2 \%$, hypertension 15.7\%), psychiatric diseases (depression, anxiety disorders $11.1 \%$ ), internal medicine and metabolic disorders (kidney disease $1.7 \%$, diabetes $4.2 \%$, gout $0.5 \%$, hypothyroidism $4.5 \%$, obesity $9 \%$ ), and other conditions, although only $43.5 \%$ thought the SARS-CoV-2 vaccine was safe. A report by the Centre for Countering Digital Hate (CCDH) published in early October 2020 warned that more than 7 million users have joined anti-vaccine groups since 2019. The study found that people who used social media to search for information about the pandemic were more hesitant in their decision to vaccinate. ${ }^{11}$

Individuals with coexisting chronic diseases should take special care of their health due to the higher risk of severe SARS-CoV-2 infection. More than $60.5 \%$ of the respondents in our study planned to be vaccinated against SARS$\mathrm{CoV}-2$. Similar results were obtained in a study conducted in the USA by Fisher et al. among 991 adults, with 571 (57.6\%) stating their intention to be vaccinated against SARS-CoV-2. ${ }^{12}$

Our study showed that almost $2 / 3$ of patients wanted to be vaccinated against SARS-CoV-2, while more than $1 / 5$ of the respondents were undecided. The most common reason mentioned by Polish patients was fear of postvaccination complications (32.1\%). Respondents were most concerned about anaphylactic shock (37.4\%). Fear of severe post-vaccination complications is one of the most frequently addressed issues by anti-vaccine groups, which aim to discourage the public from vaccinating. A CDC report dated January 6,2021 , indicates that after 1.9 million doses of the Pfizer/BioNTech vaccine were administered, there were 21 cases of severe allergic reaction, which is a $0.001105 \%$ probability of such an adverse event. To a large extent, the benefits outweigh the risks. ${ }^{13}$

Among the motivations reported by respondents to vaccinate against SARS-CoV-2, the main reason was fear of getting COVID-19 (51.4\%), while young people were more likely to indicate the desire to return to a social life (45.7\%). A survey by Larson et al. of a group of 65,819 individuals from 67 countries indicated that education increases awareness about the importance and effectiveness of vaccination, but not about its safety. ${ }^{14}$

Our study showed that patients with higher education were significantly more likely to report willingness to participate in the SARS-CoV-2 vaccination program and significantly more likely to believe in vaccine effectiveness. Individuals with higher education were more afraid of getting COVID-19 than those without an academic education, and they regarded vaccination as an opportunity to return to a social life.

Similar views as educated respondents were held by younger respondents, who were more likely to believe that vaccines should be voluntary and that the main rationale for vaccination was to return to a social life.
Older respondents, on the other hand, were more concerned about being infected with COVID-19 and were more likely to believe that vaccines should be mandatory for everyone. The respondents, depending on their age, place of residence and education, were motivated to get vaccinated in different ways. This suggests that education of all individuals, especially those at higher risk for severe SARS-COV-2 infection, is extremely important and may increase their awareness of the role and importance of vaccination.

The largest group of respondents were cancer patients (77\%). As mentioned earlier, this group is particularly at risk of severe SARS-CoV-2 infection due to immunosuppressive oncological treatment. The recommendations of Polish and global scientific societies emphasize that cancer patients and people involved in their therapeutic process should be vaccinated as a priority, regardless of age or coexisting diseases. ${ }^{13}$

Due to the innovative nature of vaccines, there are discussions about their safety and vaccine feasibility in cancer patients. Cancer patients have not participated in clinical trials on vaccine effectiveness. However, based on previous experience with vector vaccines against the influenza virus, it should be assumed that vaccines against SARSCoV-2 are safe for them. ${ }^{15,16}$

Among the respondents, oncology patients were less likely to believe in the safety of vaccines than patients with other conditions ( $40.4 \%$ compared to $53.9 \%$ ), thus their education is extremely important. It is worth emphasizing that vaccines are safe and do not impair cancer treatment, nor should they be a reason for vaccine postponement. Their effectiveness may be limited during immunosuppressive therapy (chemotherapy), but in combination with the use of personal protective equipment, they are an effective strategy in the fight against coronavirus. Immunotherapy, hormonal therapy and targeted therapy do not impair patients' immune response.Their effectiveness in cancer patients is on the same level as in the general population.

Our study found that cancer patients were less likely than patients with other conditions to report willingness to be vaccinated against coronavirus $(58.8 \%$ compared to $66.3 \%)$, although the difference was not statistically significant. The same reasons for not wanting to vaccinate dominated in both groups: fear of complications (33\% compared to $29 \%$ ) and disbelief in vaccine effectiveness (12.6\% compared to $9.8 \%)$. It is also worth mentioning that the motivation for vaccination in internal medicine patients was the desire to return to a social life and the fear of exposing relatives to coronavirus infection significantly more often than in cancer patients.

\section{Limitations}

Our study has several limitations. Firstly, we did not verify that the patients actually suffered from the diseases indicated. Secondly, a small proportion of respondents 
were men and the vast majority of respondents were cancer patients. Lastly, the questionnaire used in the survey was not validated.

\section{Conclusions}

The vast majority of cancer and medical patients want to be vaccinated against COVID-19. More than half of the respondents did not believe that the COVID-19 vaccine would be safe for them. The most common fear was the occurrence of anaphylactic shock following the administration of the vaccine. Educating cancer and other patients about the safety and effectiveness of the vaccine, as well as the use of additional protective measures against infection, is an extremely important element of prevention during the COVID-19 pandemic.

\section{ORCID iDs}

Joanna Kufel-Grabowska (D) https://orcid.org/0000-0002-5724-9961 Mikolaj Bartoszkiewicz (D) https://orcid.org/0000-0002-8728-5998 Rodryg Ramlau (1) https://orcid.org/0000-0002-3199-2298 Maria Litwiniuk (D) https://orcid.org/0000-0001-8428-3877

\section{References}

1. World Health Organization (WHO). Coronavirus (COVID-19) Dashboard, https://covid19.who.int. Accessed April 1, 2021.

2. Sung, H, Ferlay, J, Siegel, RL, et al. Global Cancer Statistics 2020: GLOBOCAN estimates of incidence and mortality worldwide for 36 cancers in 185 countries. CA Cancer J Clin. 2021;1(3):209-249. doi:10. 3322/caac. 21660

3. Krajowy Rejestr Nowotworów. Nowotwory złośliwew Polscew 2018 roku. http://onkologia.org.pl/wp-content/uploads/Nowotwory_2018.pdf. Accessed April 1, 2021.

4. Federal Drug Administration. Pfizer-BioNTech COVID-19 vaccine. https://www.fda.gov/emergency-preparedness-and-response/corona virus-disease-2019-covid-19/pfizer-biontech-covid-19-vaccine. Accessed March 8, 2021.
5. European Medicines Agency. EMA recommends COVID-19 Vaccine AstraZeneca for authorisation in the EU. https://www.ema.europa eu/en/news/ema-recommends-covid-19-vaccine-astrazeneca-autho risation-eu. Accessed March 8, 2021.

6. European Society for Medical Oncology (ESMO). COVID-19 vaccination in cancer patients: ESMO statements. https://www.esmo.org/ covid-19-and-cancer/covid-19-vaccination. Accessed April 1, 2021.

7. Dooling K, McClung N, Chamberland M, Marin M, Wallace M, Bell BP, et al. The Advisory Committee on Immunization Practices' interim recommendation for allocating initial supplies of COVID-19 vaccine - United States, 2020. MMWR Morb Mortal Wkly Rep. 2020;69(49): 1857-1859. doi:10.15585/mmwr.mm6949e1

8. Ribas A, Sengupta R, Locke T, et al. Priority COVID-19 vaccination for patients with cancer while vaccine supply is limited. Cancer Discov. 2021;11(2):233-236. doi:10.1158/2159-8290.CD-20-1817

9. El-Shakankery KH, Kefas J, Miller R. COVID-19, the future vaccine and what it means for cancer patients on immunotherapy. Front Oncol. 2021;10:631611. doi:10.3389/fonc.2020.631611

10. Chong CR, Park VJ, Cohen B, Postow MA, Wolchok JD, Kamboj M. Safety of inactivated influenza vaccine in cancer patients receiving immune checkpoint inhibitors. Clin Infect Dis. 2020;70(2):193-199. doi:10.1093/cid/ciz202

11. Burki T. The online anti-vaccine movement in the age of COVID-19. Lancet Digit Health. 2020;2(10):e504-e505. doi:10.1016/\$2589-7500 (20)30227-2

12. Fisher KA, Bloomstone SJ, Walder J, Crawford S, Fouayzi H, Mazor KM. Attitudes toward a potential SARS-CoV-2 vaccine: A survey of U.S. adults. Ann Intern Med. 2020;173(12):964-973. doi:10.7326/M20-3569

13. Centers for Disease Control and Prevention (CDC). COVID-19 Vaccination. https://www.cdc.gov/vaccines/covid-19/index.html. Accessed April 1, 2021

14. Larson $\mathrm{HJ}$, de Figueiredo $A$, Xiahong Z, et al. The state of vaccine confidence 2016: Global insights through a 67-country survey. EBioMedicine. 2016;12:295-301. doi:10.1016/j.ebiom.2016.08.042

15. Polack FP, Thomas SJ, Kitchin N, et al. Safety and efficacy of the BNT162b2 mRNA Covid-19 vaccine. N Engl J Med. 2020;383(27): 2603-2615. doi:10.1056/NEJMoa2034577

16. National Institutes of Health ( $\mathrm{NIH}$ ). Peer-reviewed report on Moderna COVID-19 vaccine publishes. https://www.nih.gov/news-events/ news-releases/peer-reviewed-report-moderna-covid-19-vaccinepublishes. Accessed April 1, 2021. 